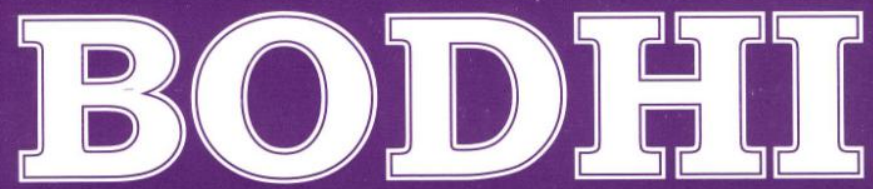

An Interdisciplinary Journal

ISSN: 2091-0479

Department of Languages and Mass Communication School of Arts

Kathmandu University

Bodhi, 4 (1), 81-99. ISSN 2091-0479. (C) 2010 Kathmandu University 


\section{Globalization, pedagogy and international literature for children and young adults}

- Hari R. Adhikari

In the article "Beyond Nation-State Paradigms: Globalization, Sociology, and the Challenge of Transnational Studies," William I. Robinson (1998) argues that "new interdisciplinary transnational studies" should be predicated on a paradigmatic shift in the focus of social inquiry. He demands for "a break with the 'nation-state framework of analysis' that continues to guide much macrosocial inquiry" as the framework is "incapable of explaining phenomena that are transnational in character" (p. 562). Clearly, it is a call for a break from the old ontological and interpretive framework in the field of international studies. In his words, "We need to lower disciplinary boundaries and barriers to a holistic approach" ( $\mathrm{p}$. 590). His emphasis on holistic approach to transnational studies and especially transnationalization of education is worth quoting at length,

... transnational studies should interact with all area studies by helping to illuminate the changes globalization brings to each region as components of a global system. Perhaps the principal contribution of such a field, therefore, is less to open new avenues of research into the social universe than to recast numerous current social science research agendas in light of globalization, to expunge nation-state centrism in the process, and to explore the complex scenarios that emerge from the dialectic interaction of descendant nation-state and ascendant transnational spaces. At a concrete level, transnational studies may enrich multiple lines of research that have developed over the past two decades by providing new paradigmatic points of reference (the transnational es-sence of phenomena under study) and a 
macrostructural-historical context (globalization) for this research. (p. 589-590)

Robinson is optimistic that this model of transnational studies and research can incorporate different areas like new international labor studies, new global population and transnational migration studies, the global cities literature and the new urban studies, the new global environmental studies and the new world order studies. I believe that the recently emerging field of children's literature can very well apply this model because it emphasizes on the break with the boundaries of any kind by transcending the old interpretive structure that has never been able to do away with stereotyping and stigmatization. This paper, by concentrating on pedagogy and globalization, will argue that transcending the nation-state framework of analysis in education should begin with the teaching of art, culture and literature from elementary school if they are to be prepared for identifying themselves as the citizens of the world. My contention is that even the multicultural focus in American school education, for instance, has not been able to move outside the narrow categories surrounding the domestic groupings like black, white, Latina/o, natives, etc. Only by breaking these still limited analytical categories surrounding the hyphenated and non-hyphenated Americans and opening up new avenues for children to the understanding of international cultures, children can be prepared for the more complex world they are likely to encounter in the near future. Likewise, countries like Nepal which are heading towards pluralistic democracy should learn lesson from the countries that have witnessed the pros and cons of nation-centered multiculturalism.

I would like to begin by introducing the context of American schools. According to Donna M. Gollnick and Phillip C. Chinn (2002) American schools have increasingly become culturally diverse. According to the data they present, in 2002, the students of color comprised more than one third of the school population (p. 4). If the same demographic trend continues, 
they predict, this group will represent nearly half of the elementary and secondary population by 2020 . Indeed, the school demographic has been changing rapidly due to globalization. Therefore educators today are faced with an overwhelming challenge to prepare students from diverse cultural backgrounds to live in a rapidly changing society and a world in which some groups have greater societal benefits than others because of race, ethnicity, gender, class, language, religion, ability, or age. Gollnick and Chinn write,

It is not only ethnic and racial diversity that is challenging schools. During the past 35 years, new waves of immigrants have come from parts of the world unfamiliar to many Americans. With them have come their religions, which seem even stranger to many Americans than these new people. . . The United States has not only become multicultural nation, but it has also become a multireligious society. (p. 5)

In such multicultural muntinational world, the student's cultural backgrounds are used to develop effective classroom instruction and school environments. However, the problem of intolerance and xenophobia still continues in American school environment.

Even though multiculturalism, globalization and transnationalization have become buzz words in academia, Gollnick and Chinn agree that there is still a long way to go in the matter of change in American understanding due to the deep-rooted conceptual framework based on binaries. The root cause of this problem lies in the literature used in American school curriculum which, according to them, is very much localized and schools are skeptical in including texts about cultures from and about the outside world. They are just prepared to understand their nation, their people and their own problems, with little exposure outside the community or country at large. Such a curriculum poses more serious problems to the thousands of children entering the U.S. from other parts of the world. More serious problem of understanding lies among the children of immigrant parents with diverse 
cultural, national and religious backgrounds bound to work together. Besides the difficulties posed by the barriers of communication, the difference in conceptual framework and focus on nationalized curriculum is more responsible behind the difficulty in their assimilation to the mainstream.

By this, I don't mean to say that the root of this problem lies only in American education system; the conceptual framework already built in among the immigrants is equally responsible. So, in this paper, I proceed with a very brief note on the concept of globalization, discuss the new conceptual framework of transnationalization in education and finally show how internationalization and "diasporization" of children's literature can help prepare the future citizens for the globalized world in which they will develop more critical perspective towards the realities they have to face every day.

Globalization, in a common parlance, is often taken to have a single trajectory or logic resulting in an increased uniformity or homogeneity across the globe. In this sense, globalization is universalizing the Western goods, cultures, conceptual frameworks by making the numerous non-Western ones extinct. Such understandings, Richard Edward and Robin Usher (2008) argue, "simplify the processes at work and, in a sense, to distance oneself from the very complex effects on space, place and identity that globalizing processes bring to the fore" (p. 22). They state that while globalization has resulted in the spread of 'Western' institutions across the globe, that very trend produces a pressure for local autonomy and identity. In other words, globalization is about examining places as simultaneously traversed by the global and local in ways that have been intensified by the contemporary compression of space and time. According to Roland Robertson (2008), "Globalization as a concept refers both to the compression of the world and the intensification of the world as a whole" (p. 87). Tracing the roots of globalization, Robertson says that the steady growth in map-making and its globalization, the interpenetration of modes of 'traveler' tales,' the growth of postal services, the increase in 
the spread of travel, the early rise of tourism - all these, and still other, developments lay in the background to the rapid trends of the crucial take-off period of modern globalization. Whereas Meyer et. al see that " $[\mathrm{t}]$ he colossal disaster of World War II may have been a key factor in the rise of global models of nationally organized progress and justice, and the Cold War may well have intensified the forces pushing human development to the global level" (p. 86). Wheresoever the root of globalization is located, and whatever way we define it, it has become indispensable. As Lechner and Boli sum up, "globalization is the set of processes by which more people become connected in more and different ways across ever greater distances" (p. 4).

With this note on the concept of globalization, I will briefly present the mutually contradicting views about globalization among its thinkers. In the eyes of globalization supporters, with the minimal role for the state, the activities of multinational corporations in free and open markets have become the main engines of economic development for developing countries. To them, the globalization of capital also allows the money to flow to the most productive and efficient business ventures. This trend increases the profit levels, making the economy of the developing countries grow, and the people begin to move to the developed countries and bid their labor in more competitive labor markets. With them the culture of the developing world also moves towards the developed world and enriches itself.

By contrast, a more negative view of developing countries' integration into the global economy, often attributed to dependency or neo-Marxist theorists, holds that in the context of globalization, the activities of multinational corporations contribute to human rights abuses. Economic globalization thus exploits the developing world: cheap labor, minimal skill transmission, restrictions on technology transfers, and no longterm commitment to stay or reinvest in a country's economy. Appadurai argues that the central feature of global culture today is the politics of the mutual effort of sameness and difference to 
"cannibalize one another and thereby proclaim their successful hijacking of the two Enlightenment ideas of the triumphantly universal and the resiliently particular" (p. 103). To Appadurai, both sides of the coin of global cultural process today are products of the infinitely varied mutual contest of sameness and difference "on a stage characterized by radical disjunctures between different sorts of global flows and uncertain landscapes created in and through these disjunctures" (p. 104).

However, there are also thinkers like Joseph E. Stiglitz (2008), who maintain more balanced view towards globalization. Stiglitz, for instance, believes that globalization has meant different things in different places and "the problem is thus not with globalization but with how it has been managed" (p. 208). To me, the crux of the problem lies in how the media contribute to the creation and promotion of image of globalization as a whole and the dreams and images about a particular race or nation, and the global flow of such dreams and images. For instance, the current flow of people to America from the third world is a clear example of the effect of the much publicized image of America as a country of opportunities and the still powerful narrative of American Dream. Arguing how the triumph of capitalism and the end of socialism has ideologically become the dominant narrative in the West, and relating it with the case of "Club 51" movement in Taiwan, Kuan Hsing Chen (2007) writes, "To understand the roots of American hegemony, we need to look elsewhere, and further back" (p. 124). I find Chen's example of "Club 51" and the way the impact of the flow of US academic texts to East Asian countries in their imaginary extremely compelling. He argues,

"America" has not only been with us, but has been inside our cultural subjectivity and has been part of us, if we wish to honestly understand the cultural composite of the self or selves; that the United States has not merely defined our identities but has become the reference point of our cultural imaginary. And it is precisely by occupying this position of being the "reference point" or system of reference that "America" constitutes our 
subjectivity, and precisely because it's an imaginary referent point, it has become part of us. (p. 127)

To me, Chen's argument is the manifestation of (dis)identificantion of the Taiwanese people and the embodiment of the cultural imaginary constructed by the West, particularly the United States in the recent days.

$\mathrm{Na}$ An (2001), the second generation Korean-American writer, also portrays the phenomena of (dis)identification among the South Koreans. In the novel, Young Ju, the four year old girl, can't figure out what her grandmother means when she says, "Mi Gook [America] is only for young people to have a new start . . . Not for old people who are used-up dry fish bones". Yet, she begins to weave the dream of landing on this dreamland (P. 21). Here is the image of the girl dreaming of flying to Mi Gook:

But then my eyes find the sky. Think about flying up, up, up. Now I know where we are going. I want to run around, wag my tail like Mi Shi [the dog]. God is in the sky. Mi Gook must be in heaven and I have always wanted to go to heaven. It is just like the Good Book says. All people who love God will go to heaven someday. I love you, God, I whisper. In heaven you have to wear your Sunday dress every day so you can look pretty for God. (p. 13)

This is what the Americanized education system and the interpellating effect of media images have taught to millions of people in the third world. Not only children and young adults, but also adults find it appealing to immigrate to America. Much greater are the dreams of the people in the countries like Bhutan, Sri Lanka, Bangladesh and many African and Latin American countries where domestic political instability have rendered millions of people poorer and poorer every year.

The fantacized image of America, however, begins to crumble down as soon as they start their struggle for survival, regardless of partial economic success in their new home. For instance, as 
soon as Young Ju's family get to America, she hears one of her uncle say, "Mi Gook is almost as good as heaven. Let us say it is a step from heaven" (p. 26). It does not take long for her to realize that it is more of a hell than heaven or "a step from heaven," for those who have to undertake the course of losing battle for acceptance. How can this place be heaven when nobody understands her? When the dreams get shattered and the family breaks apart, Young Ju realizes that the American dream is just a dream that can never be materialized.

Similar is the experience of Gene Luen Yang (2006), another second generation Asian-American artist/ illustrator who portrays the struggles of Asian-American children at American schools in his graphic novel. Jin Wang dreams of an old Herbalist's wife who had once said to him, "It's easy to become anything you wish ... so long as you're willing to forfeit your soul" (p. 29). When he wakes up with headache he finds himself in an American mask. He goes to the bathroom and looks at himself in the new form. Here, Jin wants to be Americanized with an American name called Danny as he says, "A new face deserved new name" and transforms himself based on his misrecognition of himself, in Lacanian terms (p. 198).

Indeed, Yang successfully portrays the complex life of the immigrants whose identity formation is continuously affected by being trapped between the two worlds, the root culture and the target culture that is based more on fantasy than its material reality; yet, he does not propose any model to break the cultural imaginary of America. Jin's identity is a perfect example of such an immigrant self which is trapped between the Chinese roots and American "habitus," to use Pierre Bourdeu's words. I believe that unless the dreams imbedded in the American hegemony is deconstructed, millions of Jins will continue to suffer.

An important point to note here is that Yang's implicit appeal to transcend the insularity of stereotypes is not enough to resolve the problem. There has to be further emphasis on the study of 
U.S. imperialism with multicultural approach both in the U.S. and other countries, which will help unravel the root causes of tension at U.S. homes and schools. To refer back to "Taiwan and Club 51: On the Culture of US Imperialism," Kuan-Hsing Chen (2007) argues, "has something to do with the way postcolonial studies - where one would expect to find critical probing of it - have over-privileged 'English' experiences ( $p$. 119). Chen further writes,

... the study of US imperialism as internal, internalized, and interior cultural forces within Asia is a neglected area of study. It needs to be brought to the forefront of critical debate and even recognition. Without such analysis, the complexity of contemporary cultural subjectivity of "Asian," in different locales, cannot be properly explained. (p. 112)

I fully agree with Chen's idea that for understanding the roots of the problems in U.S. schools, we "need to look elsewhere, and further back." Historically, as Chen says, "America" as a cultural imaginary has, since the mid-nineteenth century, never been outside "Asia," just as "Asia" has never been outside "America" (p. 124). Therefore the problems of the immigrants in America have roots in the way its fantasized image is made in developing countries.

Britain had also created an identical image among the people in the world it had colonized. In Indians in Britain: Anglo-Indian Encounter Race and Identity, Shompa Lahiri (2000) writes,

Although English history and culture, as revealed to Indians through literature, inspired those wishing to visit England, books alone were not enough to convert desire into action. They tantalized the Indian reader with romantic visions of a sanitized Britain, where justice and democracy could be found in the enlightenment tradition. But for many it was the example of an England-returned or some kind of family intervention that proved decisive. Some parents believed that England would provide their children with a fresh start, turning to success efforts 
which had met only with failure in examinations in India. (p. 37)

Besides this romantic vision of England, Lahiri also mentions that prestige of those who had returned to India proved extremely influential among the Indians at home.

Whether it is the case of England in Lahiri's heydays or that of America in the recent years, the dream of moving to the developed nations occupies a great space in the third world psyche. I think this is one of the deepest impacts of globalization and though the context cannot be easily reversed, inculcation of more critical viewpoint could at least reduce the conflict between dream and reality among both the world youth and the immigrant families in the United States.

On the other hand, if we look at the American education system, it's been a cliché since long that America is a pluralistic country and cultural identities of Americans are based on traits and values learned as part of their ethnic origin, religion, gender, age, socio-economic status, primary language, geographic region, places of residence, and abilities or exceptional conditions. Assumptions about cultural, racial and religious diversity and their realization among the citizens are often taken for granted. For instance, Gollnick and Chinn (2002) write, "U.S. population, members of microcultures also have learned cultural traits, discourse patterns, ways of learning, values, and behaviors characteristics of the macrocultures to which they belong" (p. 18). However, there is a whole lot of literature that admit that such a realization and treatment of each individual as equal citizen in American soil is more of a myth than reality. Bullying and stigmatization based on old stereotypes have become the subject matter of writing among many immigrant writers. For instance, in "Growing up Asian in America," Kesaya Noda (1999) writes,

Sometimes when I was growing up, my identity seemed to hurtle toward me and paste itself right to my face. I felt that way, encountering the stereotypes of my race perpetuated by non-Japanese people (primarily white) 
who may or may not have had contact with other Japanese in America. "You don't like cheese, do you?" someone would ask. "I know your people don't like cheese." Sometimes questions came making allusions to history. That was another aspect of the identity. . . . I was sometimes addressed or referred to as racially Japanese, sometimes as Japanese-American, and sometimes as an Asian woman. Confusions and distortions abound. ( $\mathrm{p}$. 36-37)

Noda's experience is very much similar to that of Roland Takaki (1999), a third generation Japanese-American writer. In "A Different Mirror," Takaki includes the following conversation he had with a taxi driver in Norfolk (U.S.) that revealed him how much race matters:

The rearview mirror reflected a white man in his forties. "How long have you been in this country?" he asked. "All my life," I replied, wincing. "I was born in the United States." With a strong southern drawl, he remarked: "I was wondering because your English is excellent!" Then, as I had many times before, I explained: "My grandfather came here from Japan in the 1880s. My family has been here, in America, for over a hundred years." $\mathrm{He}$ glanced at me in the mirror. Somehow I did not look "American" to him; my eyes and complexion looked foreign. (p. 589)

Again, in American Born Chinese, Jin Wang, Wei Chen and Suzy Nakamura, are three Asian-American children who never feel that they belong to the American culture even though they were born in America. Jin is a Chinese descendant and Suzy, Japanese, but both of them become the victim of discrimination and stigmatization in the same way. In spite of Jin's reluctance to hang out with Suzy, she tells Jin about how bad she felt when one of her American classmates hurt her feelings. She says, "Today, when Timmy called me a ... chink, I realized . . . deep down inside ... I kind of feel like that all the time" (Yang, 2006, p. 187). It is not only other fellow students who misunderstand 
these children; even the teachers bring out expressions that hurt the feelings of these immigrant children. In response to Jimmy's expression "My momma says Chinese people eat dogs," the teacher says, "I am sure Jin doesn't do that. In fact, Jin's family probably stopped that sort of thing as soon as they came to the United States" (p. 31). I think this situation at American schools clarifies that American education system has not been able to cope with the changes and problems brought forth by globalization.

Unlike most other European countries, America is a considered as the country of immigrants and should have shaped its education to cope with this multicultural demographic reality. But this does not seem to be happening thus far. Here, we can clearly see why it was so likely for the teacher in American Born Chinese to take Jin for his face value. Though he was American by birth and never mentioned whether he had been to China or not, his physical appearance is enough for the teacher to believe that he must have come "all the way from China" (p. 30). She could have been careful enough to utter his name correctly and ask him where he had come from. Despite being a teacher, she could never imagine the gravity of the impact of such an incident in the psyche of a child. Then, how can the children be expected to understand the feelings of their "alien" friends before humiliating them with stereotypes. For instance, a rumor circulates in the class that Suzy (another Asian girl) and Jin were arranged to be married on her thirteenth birthday. Now, simply because a guy of similar race joins the class, Suzy becomes an object for ridicule among the classmates. Isn't this enough to touch the fragile psyche of the children? This indicates that children have not been taught to see through the stereotypes prevailing in the society. Clearly, it implies that the children of immigrant parents, irrespective of their country of origin, share identical fate of being misunderstood and stereotyped in America schools. Noda's further writing is a case in a point,

A voice from my childhood says: "You are other. You are less than. You are unalterably alien." This voice has 
its own history. We have indeed been seen as other and alien since the early years of our arrival in the United States. . . . The Japanese fell natural heir to the same antiAsian prejudice that had arisen against the Chinese. (p. 37)

Here, Noda clearly demonstrates that even after making a long history of living in the United States, Asian-Americans have had to experience discrimination. Similar is the case of AfricanAmericans and Latino/as. The American education system has still not been able to ameliorate the problem which is likely to worsen with the increased flow of people from other unfamiliar parts of the world.

In order to avoid such problems, Edwards and Usher recommend the "spatializing and (dis)locating" pedagogies in which the pedagogic spaces of the educational institution is no longer isolated from those of the home, the street and the workplace, etc. each encompassing a range of pedagogies through which people learn to be and become in specific ways (p. 76). They suggest that we move from a focus on teaching and learning as bounded practices to an examination of new and complex patterns of interconnectedness, and the pedagogic spaces and socio-cognitive, socio-practical, socio-semiotic and socio-affective possibilities that are both opened up and excluded by the multiple interconnectedness of globalization ( $\mathrm{p}$. 76). In this approach, learners will be exposed to different living and working conditions where they will get opportunities to encounter reality face to face.

According to Edwards and Usher, the practices of (dis)location are neither easy nor straightforward. However, they provide the basis for pedagogical forms which recognize meaning-making and the mediation of meaning as central to learning. They write, In order to identify and to recognize how we are identified, we need to be reflexively aware of the forms of counter- and dis- identification that make this possible. this in itself undermines strongly central notions of 
identification and constitutes the possibility of diasporic identities, (dis)located and at once global and loca. It is for such reasons that we find the notion of (dis)location both resonant with out view of globalization and capable of spatialising as well as narrating pedagogic practices as part of globalisation. (p. 152)

In addition to advocating for the approach of dis-identification and (dis)location, Edwards and Usher also state that "workplace learning," "work related learning" and "work-based learning" have all become familiar framings within the contemporary discourses of education. According to them, the current strong support for policies of lifelong learning in many parts of the globe is a feature of these discourses where it is articulated as a necessity arising from a changing economic order influenced by globalizing processes (p.78-79). I think this all could make more applicable model for the teaching of literature for children by "diasporization" and transnationalization of courses.

Though this concept might not be easy to implement at the Kindergarten through grade 12 (K-12) levels, it can be very useful for higher education. In addition, this notion can be assimilated with the approach of problem based learning as a part of multicultural education. Problem-based learning (PBL) is an approach in which emphasis is given to creating learning environment where problem drives the learning. That is, before students learn some knowledge, they are given a problem. Here, the problem of identification and dis-identification is posed in such a way that students discover the need to learn some new knowledge before they can solve the problem.

Before I conclude, I would like to connect the pedagogy of (dis)location with the approach of multiculturalism already in practice in U.S., Canada and many other countries. I believe that multicultural approach to elementary to high school education needs to be revised so as to make it more transnational and transcultural so that children develop the skills of looking at the world from other's perspectives. 
Looking at the world from perspective of the child within, one that is less biased by nature, is often taken as the first step towards giving space to another voice. In "Self, Other, and Other Self: Recognizing the Other in Children's Literature" Roderick McGillis (1997), argues that all of us have both "canny" and "uncanny" selves. Using Julia Kristeva's notion of the foreigner within us as "the hidden face of our identity, the space that wrecks our abode, the time in which understanding and affinity flounder," McGillis writes, “... each attempt at story is an attempt to understand what it is like to be an Other (p. 220). Arguing further, McGillis asserts, "to construct a character is to make an imaginative leap into the possibility of other lives" and telling our stories and listening to that of others enables us to look at the "uncanny" self, which is often an enriching experience. I find that this model of teaching literature goes along with Edwards and Usher's model of "(dis)locating" pedagogy for the globalized world. They make it clear when they say,

We also believe that notions of diaspora space and (dis)location have the potential to offer a means of negotiating the seeming paradox of the hybrid universal and particular, the global and local, and the endlessness of positioning and repositioning - and, hence of learning - which this implies. The mapping of pedagogies of (dis)location brings to the fore the very locatedness of subjects, in both senses of persons and bodies of knowledge, thereby offering a framework for reconceptualizing pedagogy in contemporary conditions. (p. 164)

I think a combination of these two models, multiculturalism and "spatializing" can function as the foundation of pedagogy of literature for children at the present age of globalization.

As the Western thought had been permeated with a style of thinking based on binary opposition for ages, our rationality has still been dictating the advocacy of either one thing or another or recognizing gradations on a linear scale of some sort. 
According to Hélène Cixous (1986), the oppositional terms like West and East, adult and children, White and Black, able and disabled, among others, are locked into a relationship of conflict, and moreover, this relationship is one in which one term must be repressed at the expense of the other (p. 211). Based on the above discussion, I am convinced that self and other are, of necessity, mutually constituted. Therefore, as argued by Julia Kristeva, the ultimate goal of teaching should be to break the ontology of othering for promoting tolerance among people with differences.

A similar spirit can be observed in "Metatheorizing the Dialectic of Self and the Other" where Adrian Carr and Liza A. Zanetti (1999) argue that if other is not viewed as a challenge to self, defensiveness and hostility have only cameo roles to play (p. 337). The privileging and enforcement of self over other, they assert, not only represents tremendous arrogance but also contains the antithesis of arrogance: humility. The privileged self seeks to dominate and marginalize other by casting other as nothing, with self as absolute. In this regard, I find want to buy into Kristeva's argument that only by recognizing our own "disturbing otherness" can we exorcise the demon that is actually the "apprehension generated by the projective apparition of the other at the heart of what we persist in maintaining as a proper, solid "us"' (p. 192). I think the pedagogy of literature for children in the present age of globalization should aim at exorcising that demon among us so as to build the atmosphere of trust and security among each other.

Finally, though American school system has long been emphasizing on the multicultural approach to education, multiculturalism has still remained either amorphous or confined to localization and nationalization. Due to the lack of absolute categories and definitions of multiculturalism, no alternative approach has been able to replace it by fulfilling the need of the globalized world. I believe that the sociopolitical goal of multiculturalism for the contemporary age should be to 
challenge, in terms of Mingshui Cai (2002), "the existing canon by expanding the curriculum to include literature from a wide variety of cultural groups (p. 59). The multicultural pedagogy should be more multidisciplinary, transnational, and diasporic as Edwards and Usher have argued. It should be able to break with the disciplinary and political borders. A multicultural classroom, in this context, should be framed in such a way that students from homogeneous and/or heterogeneous cultures engage on the issues relating to diverse cultures boosted by the readings, activities and assignments through the process of (dis)identification.

To conclude, despite the existing debate around multiculturalism, this approach has remained the most effective pedagogy for teaching literature for children until at least until the emergence of a more transnationalized form of pedagogy. In terms of Edwards and Usher, we must aim at a more "diasporized" and "(dis)locating" version of pedagogy that addresses the problems of the diversity of cultures consisting of as many categories as possible from: race, immigrants, economically underprivileged, disables, sexual minorities, children, cross-linguistic, cross-cultural, and cross border issues, among others.

\section{References}

An, N. (2001). A Step from heaven. New York: Speak.

Cai, M. (2002). Multicultural literature for children and

young adults: Reflections on critical issues. Westport:

Greenwood Press.

Appadurai A. (2008). Disjuncture and difference in the global

cultural economy. In F. J. Lechner, \& J. Boli (Eds.), The globalization reader ( $3^{\text {rd }}$ ed) (pp. 95-104).. Massachusetts: Blackwell.

Carr, A., and Zanetti, L. A. (1999). Metatheorizing the dialectic of self and other: The psychodynamics in work organizations. American Behavioral Scientist, 43 (2), 324-345. 
Chen, K. H. (2007). Taiwan and club 51: On the culture of US imperialism. In R. Wilson, and L. C. Christopher (Eds.), The worlding project: Doing cultural studies in the era of globalization (pp. 109-131). California: North Atlantic Books.

Cixous, H. (1986). Sorties. In H. Cixous \& C. Clement (Eds.), The newly born woman (pp.201-219). Manchester: Manchester University Press.

Edward, R. \& R. Usher (2008). Globalization and pedagogy: space, place and identity. New York: Routledge.

Gollnick, D. M. \& P. C. Chinn (2002). Multicultural education in a pluralistic society $\left(6^{\text {th }}\right.$ ed). Ohio: Prentice Hall.

Kristeva, J. (1991). Strangers to ourselves. Trans. L. Roudiez. New York: Columbia University.

Lahiri, S. (2000). Indians in Britain: Anglo-Indian encounters, race and identity, 1880-1930. London: Frank Cass.

McGillis, R. (1997). Self, other, and other self: Recognizing the other in children's literature. The lion and the unicorn 21 (2), 215-229.

Meyer, J. W. et al. (2008). World society and the nation-state. In F. J. Lechner and J. Boli (Eds.), The Globalization reader ( $3^{\text {rd }}$ ed.) (pp.78-86). Massachusetts: Blackwell.

Noda, K. (1999). Growing up Asian in America. In R. Bass, (Ed), Border texts: Cultural readings for contemporary writers (pp. 37-42). New York: Houghton Mifflin.

Robertson, R. (2008). Globalization as a problem. In F. J. Lechner, and J. Boli (Eds.), The Globalization reader ( $3^{\text {rd }}$ ed.) (pp.87-94). Massachusetts: Blackwell

Robinson, W. I. (1998). Beyond nation-state paradigms:

Globalization, sociology, and the challenge of transnational studies. Sociological Forum, 13 (4), 561594.

Stiglitz, J. E. (2008). Globalism's discontents. In F. J. Lechner and J. Boli (Eds.), The Globalization reader ( $\left.3^{\text {rd }} \mathrm{ed}\right)$ (pp. 208-215). Massachusetts: Blackwell.

Takaki, R. (1999). A different mirror. In R. Bass, (Ed), Border texts: Cultural readings for contemporary writers (pp. 589-596). New York: Houghton Mifflin. 
Yang, G. L. (2006). American born Chinese. New York: First Second.

Mr. Adhikari is a Lecturer at Ratna Rajya Laxmi Campus (Tribhuvan University). $\mathrm{He}$ is Currently Pursuing $\mathrm{PhD}$ in English Studies at Illinois State University, Normal, U.S.A. 